\section{Modificaciones del ambiente oral en el tratamiento con ortodoncia fija}

\section{Modifications of the oral environment due fixed orthodontic treatment}

\section{Resumen}

Objetivo. Evaluar las condiciones del ambiente oral de distintos sectores de la boca de pacientes previo y durante el tratamiento ortodóntico. Métodos. Estudio prospectivo en 46 pacientes con tratamiento de ortodoncia fija. Los parámetros clínicos, microbiológicos de saliva y placa bacteriana fueron registrados antes del tratamiento $(\mathrm{t} 0)$ y a los 45 (t1), 90 (t2) y 135 días ( $\mathrm{t} 3$ ) del inicio. Resultados. Antes del tratamiento se registraron valores elevados del componente "cariados" del índice CPO-D y niveles regulares del IHOs. El 57\% de los pacientes mostró apińamiento dental inferior. Durante el tratamiento, el índice de placa ortodóntica IPO disminuyó respecto al IHOs a t0, aunque mantuvo valores no deseables para la salud bucal $(p=0,001)$. La capacidad amortiguadora disminuyó en t1 y t2 pero recuperó los valores iniciales en t3 $(p=0,001)$. Se aislaron Streptococcus mutans, Candida albicans y Lactobacillus en todas las muestras de placa bacteriana, con un aumento significativo en el sector posterior $(p<0,0001)$. Los niveles de $S$. mutans, Lactobacillus y $\alpha$-amilasa salival en la placa bacteriana de la zona posterior aumentaron durante el tratamiento ( $p=0,0002 ; \mathrm{p}=0,002 \mathrm{y} \mathrm{p}=0,0059$, respectivamente). Conclusiones. La conjunción de factores de riesgo cariogénico, tales como apiñamiento dental, baja capacidad amortiguadora salival, altos niveles de $\alpha$-amilasa y $S$. mutans en la placa bacteriana, altos valores de IPO y el bajo flujo salival a tiempos cortos, demuestra la importancia del monitoreo individualizado de los pacientes al inicio el tratamiento ortodóntico, en especial en los sectores bucales de difícil acceso para la higiene bucal.

Palabras clave: Aparatos ortodónticos; Saliva; Placa bacteriana (fuente: DeCS BIREME).

\section{Artículo Original}

Verónica Socorro Vera Cucchiaro ${ }^{1, a}$, Silvina Ruth Barembaum ${ }^{1, b}$, Ana Isabel Azcurra ${ }^{1,0}$

${ }^{1}$ Universidad Nacional de Córdoba, Facultad de Odontología, Córdoba, Argentina.

a Doctor en Odontología.

b Doctor en Ciencias de la Salud.

c Doctor en Química.

\section{Correspondencia:}

Ana Isabel Azcurra: ana.azcurra@unc.edu.ar. Departamento de Biología Bucal, Facultad de Odontología, Universidad Nacional de Córdoba. Haya de la Torre sn. Pabellón Argentina, Ciudad Universitaria. CP. 5000.

Córdoba. Argentina.

ORCID: 0000-0001-6322-6873

\section{Coautores:}

Verónica Socorro Vera Cucchiaro: veronica.vera.cucchiaro@unc.edu.ar

ORCID: 0000-0001-9155-2502

Silvina Ruth Barembaum: silvina.barembaum@unc.edu.ar ORCID: 0000-0003-3477-7910

\section{Editor:}

Donald Ramos-Perfecto

Universidad Nacional Mayor de San Marcos, Perú

Conflicto de intereses: los autores declaran no tener conflictos de interés.

Fuente de financiamiento: este trabajo fue subsidiado por la Secretaría de Ciencia y Técnica, Universidad Nacional de Córdoba, Argentina, Res SeCyT UNC N $411 / 18$.

Recibido: 01/07/21

Aceptado: $17 / 08 / 21$

Publicado: 21/01/22 
at $\mathrm{t} 1$ and $\mathrm{t} 2$ but recovered to initial values at $\mathrm{t} 3(\mathrm{p}=0.001)$. Streptococcus mutans, Candida albicans, and Lactobacillus were isolated in all the bacterial plaque samples, with a significant increase in the posterior sector $(\mathrm{p}<0.0001)$. Levels of $S$. mutans, Lactobacillus, and $\alpha$-salivary amylase in the bacterial plaque of the posterior area were increased during treatment $(\mathrm{p}=0.0002 ; \mathrm{p}=0.002 ; \mathrm{p}=0.0059$, respectively). Conclusions. The conjunction of cariogenic risk factors, such as dental crowding, low salivary buffering capacity, high levels of $\alpha$-amylase and $S$. mutans in bacterial plaque, high values of OPI, and low salivary flow at short times, demonstrates the importance of individualized monitoring of patients at the beginning of orthodontic treatment, especially in oral sectors where oral hygiene is more difficult.

Keywords: Orthodontic appliances; Saliva; Dental plaque (source: MeSH NLM).

\section{Introducción}

El tratamiento ortodóntico se ha incrementado en los últimos años con fines estéticos y funcionales. Sin embargo, en los pacientes bajo este tratamiento se incrementa el riesgo de padecer patologías bucales asociadas a la presencia de placa bacteriana, como la enfermedad periodontal y la caries dental ${ }^{1,2}$. Entre los componentes de la ortodoncia fija, se destacan los aditamentos ortodónticos por generar nuevas áreas de retención y acumulación de placa bacteriana, pues conducen a cambios microbiológicos que pueden ocasionar alteraciones que afecten a los tejidos duros y blandos del hospedador ${ }^{3}$. Algunos autores han descrito que la aparatología fija puede modificar cualitativa y cuantitativamente la distribución de la microbiota oral, aumentando la población de Streptococcus mutans (S. mutans) y Lactobacillus tanto en la placa bacteriana como en la saliva durante el tratamiento con aditamentos ortodónticos, aún en tiempos cortos ${ }^{4}$. Si bien S. mutans es parte de la flora natural de la cavidad bucal, la presencia de la aparatología fija puede modificar las condiciones estomatológicas, con un descenso sostenido y prolongado del $\mathrm{pH}$ de la placa bacteriana ${ }^{2,5}$. Se ha reportado un incremento de las unidades formadoras de colonias (UFC) de S. mutans y Lactobacillus después del cementado de los aditamentos ortodónticos al esmalte dental y una correlación positiva con la presencia de caries ${ }^{6,7}$. La adhesión y colonización de bacterias cariogénicas a los aparatos fijos podría favorecer el desarrollo de placa bacteriana inducida por el tratamiento ortodóntico sobre la superficie del diente y conducir a desmineralización del esmalte adyacente a los aparatos fijos de ortodoncia. Otro microorganismo que puede cohabitar la placa bacteriana es la Candida albicans, una levadura comensal que está presente hasta en el $60 \%$ de los individuos inmunocompetentes ${ }^{8}$. Su habilidad para convertirse en microorganismo patógeno se atribuye a una serie de factores locales que pueden influir, como la presencia prótesis dentales fijas y removibles, y aditamentos ortodónticos que favorecen el desarrollo de este hongo ${ }^{8}$.

La formación de la placa bacteriana sobre los aditamentos ortodónticos resulta de complejas interacciones entre levaduras, bacterias, nutrientes y componentes salivales e incluso proteínas séricas. La presencia de enzimas e iones calcio salivales puede influir en el mantenimiento de la salud bucal durante el tratamiento con aditamentos ortodónticos. Entre ellas, la $\alpha$-amilasa salival, que es la enzima más concentrada y activa en la saliva, ha sido reconocida por su participación en la formación de la placa bacteriana, como receptor de adhesión bacteriana a la superficie dentaria y su alta afinidad por los estreptococos, demostrando su multifuncionalidad ${ }^{9}$. Sumado a esto, la $\alpha$-amilasa salival en la placa bacteriana mantiene su capacidad de hidrolizar el almidón a glucosa, que al ser metabolizado por la microbiota cariogénica produce ácido láctico en la proximidad del esmalte dental y la consecuente producción de caries dental. Además, las variaciones de los iones calcio en la placa bacteriana pueden reflejar una desmineralización local incipiente ${ }^{10}$. Algunos estudios han observado efectos no deseados en las condiciones salivales, como modificaciones en el flujo, el $\mathrm{pH}$ y la capacidad amortiguadora de los pacientes, así como la acumulación de placa bacteriana ${ }^{11,12}$. Sin embargo, no hay consenso sobre cómo se modifican estos parámetros tanto en la saliva como en la placa bacteriana en estas condiciones. Otro factor que puede sumarse al deterioro de la salud bucal es el tiempo de tratamiento con ortodoncia, que ha mostrado ser un factor importante en el desarrollo de la placa bacteriana asociada al tratamiento ${ }^{13}$.

El tratamiento de ortodoncia es un método eficaz para corregir la maloclusión, y es necesario tener una comprensión profunda de los cambios que pueden ocurrir en la cavidad bucal durante el tratamiento ortodóntico antes de su comienzo. El posicionamiento y alineamiento dentario mediante el uso de aditamentos ortodóncicos es un factor a tener en cuenta ya que aumenta la retención de placa bacteriana ${ }^{14}$. Además, se ha descrito la dificultad de la higiene bucal en particular en la región posterior de la boca ${ }^{15}$; esta situación puede agravarse en presencia de otros aditamentos bucales ${ }^{16}$. Mantener la salud de los tejidos periodontales y dentales durante el tratamiento ortodóntico es una prioridad. La evaluación periodontal antes del inicio del tratamiento ortodóntico es protocolar para evitar secuelas post tratamiento ${ }^{17}$. Así mismo, es fundamental que el odontólogo realice una valoración del riesgo de caries de cada paciente antes de iniciar el tratamiento ${ }^{2}$.

A fin de comprender las modificaciones que se producen durante la fase inicial del tratamiento de ortodoncia, el 
objetivo de este trabajo fue describir las condiciones del ambiente bucal de los pacientes previo al tratamiento ortodóntico y evaluar parámetros bioquímicos y microbiológicos salivales y de la placa bacteriana de distintos sectores de la boca de pacientes bajo tratamiento ortodóntico fijo a tiempos cortos.

\section{Métodos}

Se realizó un estudio prospectivo en pacientes con indicación de tratamiento ortodóntico para la corrección del posicionamiento y rotación de sus elementos dentarios. La muestra incluyó 46 pacientes (22 varones y $24 \mathrm{mu}$ jeres, entre 18 y 35 años), que asistieron a la Fundación CREO (Centro de Rehabilitación Estética Odontológica), ciudad de Córdoba, Argentina, para el tratamiento de ortodoncia con aditamentos ortodónticos metálicos vestibulares (Synergy, USA). Fueron excluidos los pacientes con enfermedades sistémicas o crónicas o medicados con tratamiento prolongado con fármacos antimicrobianos o que produzcan hiposialia, uso de corticoides y otros antiinflamatorios. Los pacientes firmaron el consentimiento informado previo a comenzar el estudio (comité de Ética Polo Hospitalario, Provincia de Córdoba No 139/12 y comité de Ética Facultad de Odontología, Universidad Nacional de Córdoba No 49/13).

Recolección de datos clínicos y muestras biológicas. Se registraron los datos clínicos y recolectaron las muestras biológicas a distintos tiempos del estudio: previo a la colocación de los aditamentos ortodónticos $(\mathrm{t} 0)$ y a los 45 días (t1), 90 días (t2) y 135 días (t3) de la colocación de la aparatología ortodóntica. Los tiempos seleccionados coincidieron con los controles programados para el tratamiento.

Los datos clínicos evaluados a t0 fueron: el índice de $\mathrm{Hi}$ giene Oral Simplificado de Green y Vermillón (IHOs) ${ }^{18}$, el índice de Quigley y Hein (IQH) ${ }^{19,20}$ y el índice CPO-D. A t $>0$ se determinó además el índice de placa ortodóntica (IPO) ${ }^{21}$.

Los pacientes fueron instruidos para no ingerir alimentos ni líquidos dos horas antes de la toma de las muestras ${ }^{8}$. Las muestras de placa bacteriana se recolectaron de la región anterior y posterior de ambas arcadas a los diferentes tiempos ( $\mathrm{t} 0, \mathrm{t} 1, \mathrm{t} 2, \mathrm{y} \mathrm{t} 3)$ y de las cuatro caras de los aditamentos ortodónticos utilizando un microcepillo, previa remoción de la saliva con un secado suave con aire. Las muestras de placa bacteriana fueron colocadas inmediatamente en tubos con solución fisiológica estéril para las determinaciones bioquímicas (calcio y $\alpha$-amilasa) y en caldo cerebro corazón para las determinaciones microbiológicas (Biokar, Francia). Se determinó la masa de placa dental recolectada por diferencia de peso del tubo utilizado para la recolección en una balanza analítica (límite de detección $0,1 \mathrm{mg}$; Radwag AS 220.R2, Polonia). Posteriormente, se recolectó saliva basal durante 5 minutos con el paciente sentado y previo enjuague de la boca con agua ${ }^{22}$.

Con el fin de minimizar los efectos de la variabilidad diurna en la composición salival, las muestras se tomaron entre las 9 y las 10 a.m., al menos 1 h después de las comidas y los procedimientos de higiene bucal para evitar efectos del ritmo circadiano ${ }^{11}$. Inmediatamente se registraron los siguientes parámetros: volumen total, volumen minuto, $\mathrm{pH}$ y la capacidad amortiguadora de la saliva $(\mathrm{pH}-$ metro, Hanna Instruments, Italia) ${ }^{23,24}$. Se centrifugó la saliva restante y se almacenó el sobrenadante a $-20{ }^{\circ} \mathrm{C}$ para las determinaciones bioquímicas.

Análisis microbiológico. Para el aislamiento de los microorganismos estudiados se sembraron diluciones seriadas de las muestras de saliva y de placa bacteriana de las regiones anterior y posterior de la boca en medios selectivos de cultivos: para $S$. mutans en agar mitis salivarius con bacitracina y sacarosa al 15\% (DIFCO, Becton Dickinson, Francia); para Lactobacillus spp. en agar Rogosa (Merck, Argentina) y para Candida spp. en agar Sabouraud glucosado (Biokar, Francia) y medio cromogénico (CHROMagar ${ }^{\circ}$ Candida, Francia). Las placas se incubaron en microaerofilia para S.mutans y Lactobacillus spp. y en aerobiosis para Candida spp. por $48-72 \mathrm{~h}$ a $37^{\circ} \mathrm{C}$. Posteriormente se realizó el recuento de colonias, expresándolas como unidades formadoras de colonias (UFC/ml de placa bacteriana o UFC/ml de saliva; contador de colonias Arcano J-2 Digital, China). La identificación bioquímica de las cepas de $S$. mutans y Candida se realizó mediante características morfológicas y pruebas bioquímicas convencionales de fermentación de azúcares (Diatabs, Rosco, Denmark) ${ }^{8,24}$.

Parámetros bioquímicos de saliva y la placa bacteriana. Se determinaron espectrofotométricamente las concentraciones de calcio (por formación del o-cresolftaleín complexona a $570 \mathrm{~nm}$ ) y $\alpha$-amilasa (por formación de 2-cloro-nitrofenil- $\alpha$-D-maltósido a $405 \mathrm{~nm}$ ) en saliva y en las muestras de placa bacteriana de las regiones anterior y posterior de la boca empleando equipos comerciales (Wiener, Argentina) 10,22,25. Las determinaciones fueron realizadas por triplicado.

Tratamiento estadístico. El análisis y procesamiento de datos se realizó a través del programa estadístico Infostat versión profesional 2020 (Facultad de Ciencias Agropecuarias, UNC, Argentina). La normalidad de los datos fue corroborada por el test de Shapiro-Wilk modificado, por lo que los valores obtenidos para las variables cuantitativas fueron resumidos mediante la media y la desviación estándar. Para la comparación de las variables en las distintas regiones de la boca se empleó la prueba t de Student para muestras apareadas. El contraste de hipótesis de diferencias a los distintos tiempos de estudios se realizó utilizando la prueba de ANOVA y al rechazar la hipótesis nula, se realizaron comparaciones por la prueba post hoc de Bonferroni. Para el análisis multivariado se usó la prueba de correspondencia, previa operacionalización de las variables cuantitativas ( $S$. mutans, Lactobacillus, IPO, pH, volumen minuto, capacidad amortiguadora salival, calcio, $\alpha$-amilasa) usando como criterio de categorización la mediana. Se estableció un nivel de confianza del $95 \%$ y un error tipo I del 5\%. 


\section{Resultados}

Las modificaciones de los parámetros clínicos, bioquímicos y microbiológicos de la placa bacteriana y la saliva de los pacientes a los distintos tiempos estudiados ( $\mathrm{t} 0$, $\mathrm{t} 1, \mathrm{t} 2 \mathrm{y} \mathrm{t} 3$ ) se muestran en la tabla. Al analizar los indicadores clínicos previo al inicio del tratamiento ortodóntico (t0) se observó un predominio del componente "cariados" en el índice CPO-D y valores del IHOs y de IQH significativamente mayores en la región posterior que en la anterior de ambas arcadas maxilares $(p=0,008$ $\mathrm{y}<0,0001$, respectivamente). Los índices IHOs y IQH se asociaron con el apiñamiento inferior, observado en el $57 \%$ de los pacientes $(p<0,0001)$ pero no con el sexo de los participantes $(p>0,05)$. Además, en la saliva a t0, se aisló S. mutans en un $25 \%$ de los pacientes, Candida spp. en el 11\% y Lactobacillus spp. en el 81\%. Se observaron altos recuentos de UFC de Lactobacillus y de $S$. mutans en la placa bacteriana, siendo el sector posterior de la boca el que mostró los mayores recuentos de ambas bacterias $(p<0,0001)$. El hongo Candida se aisló de la placa bacteriana de un $35 \%$ de los pacientes. Las pruebas de identificación de especies mostraron un $85 \%$ de
Streptococcus grupo mutans y para el hongo, un 95\% fue identificado como la especie $C$. albicans. Para analizar el efecto de la edad sobre la carga microbiana, los pacientes se clasificaron en dos grupos. Para ello se utilizó la mediana, debido a la distribución no paramétrica de la edad (mediana = 23 años). El grupo de los más jóvenes mostró mayores recuentos de UFC de $S$. mutans de la placa bacteriana de las regiones anterior y posterior de la boca que el grupo de mayor edad ( $p=0,05$ y 0,006 , respectivamente). No se observó asociación entre los recuentos de UFC de la placa bacteriana y el IHOs $(p>$ $0,05)$. Se observaron valores de actividad de $\alpha$-amilasa significativamente mayores en la región posterior que en la anterior de la boca $(p=0,0004)$.

Las condiciones del ambiente bucal luego de iniciado el tratamiento ortodóntico ( $\mathrm{t} 1, \mathrm{t} 2$ y t3; Tabla) mostraron una disminución significativa en el IPO a todos los tiempos respecto a $\mathrm{IHOs}$ a $\mathrm{t} 0$, a pesar de que los valores se mantuvieron dentro de la categoría de higiene regular, no deseable para mantener la salud bucal ( $\mathrm{t} 0$ vs. $\mathrm{t}>0$; $p=0,001)$. Entre las modificaciones de los parámetros salivales producidas por el tratamiento ortodóntico, se

Tabla 1. Registro basal (t0) y a distintos tiempos de tratamiento ortodóntico (t1, t2 y t3) de los parámetros clínicos, bioquímicos y microbiológicos de la saliva y la placa bacteriana \#

\begin{tabular}{|c|c|c|c|c|}
\hline & to & t1 & t2 & t3 \\
\hline $\begin{array}{l}\text { Índice de higiene oral simplificado } \\
\text { (IHOs a t0 e IPO a t1, t2 y t3) }\end{array}$ & ${ }^{c} 2,28 \pm 0,55$ & c $1,41 \pm 0,46$ & ${ }^{c} 1,50 \pm 0,60$ & ${ }^{c} 1,24 \pm 0,55$ \\
\hline Índice de Quigley Hein (IQH) & $3,21 \pm 1,1$ & $1,89 \pm 0,96$ & $2,31 \pm 1,9$ & $2,15 \pm 1,73$ \\
\hline Dientes cariados & $5,28 \pm 3,44$ & SM & SM & $\mathrm{SM}$ \\
\hline Dientes perdidos & $3,17 \pm 3,13$ & SM & SM & SM \\
\hline Dientes obturados & $2,29 \pm 2,95$ & SM & SM & $\mathrm{SM}$ \\
\hline CPO-D & $8,5 \pm 6,3$ & SM & $\mathrm{SM}$ & $\mathrm{SM}$ \\
\hline Flujo salival (ml/min) & $0,47 \pm 0,32$ & $0,48 \pm 0,32$ & $0,37 \pm 0,40$ & $0,41 \pm 0,35$ \\
\hline Capacidad amortiguadora & d $1,14 \pm 0,73$ & ${ }^{\mathrm{d}} 0,98 \pm 0,67$ & d $0,61 \pm 0,73$ & $1,4 \pm 1,76$ \\
\hline$\alpha$ - amilasa salival (U/l) & ${ }^{g} 0,69 \pm 0,21$ & ${ }^{\mathrm{g}} 0,86 \pm 0,12$ & ${ }^{\mathrm{g}} 0,77 \pm 0,22$ & ${ }^{\mathrm{g}} 0,71 \pm 0,21$ \\
\hline Concentración de $\mathrm{Ca}^{2+}$ salival (mg/dl) & e $13,8 \pm 11,91$ & $8,87 \pm 6,14$ & $13,23 \pm 13,05$ & $14,62 \pm 12,33$ \\
\hline Candida albicans salival (UFC/ml) & $78 \pm 23$ & ND & $25 \pm 19$ & $38 \pm 34$ \\
\hline Streptococcus mutans salival (UFC/ml) & $\begin{array}{l}4,5 \times 10^{3} \pm \\
2,5 \times 10^{3}\end{array}$ & $6,7 \times 10^{3} \pm 1,0 \times 10^{3}$ & $1,3 \times 10^{4} \pm 1,1 \times 10^{4}$ & $7,2 \times 10^{3} \pm 6,5 \times 10^{3}$ \\
\hline Lactobacillus spp. salival (UFC/ml) & $\begin{array}{l}4,6 \times 10^{3} \pm \\
3,3 \times 10^{3}\end{array}$ & $2,5 \times 10^{4} \pm 1,4 \times 10^{4}$ & $2,1 \times 10^{4} \pm 1,9 \times 10^{4}$ & $1,1 \times 10^{4} \pm 1,1 \times 10^{4}$ \\
\hline$\alpha$-amilasa en región anterior (U/l) & b, h $0,33 \pm 0,25$ & ${ }^{\mathrm{h}} 0,62 \pm 0,28$ & ${ }^{\mathrm{h}} 0,70 \pm 0,19$ & ${ }^{\mathrm{h}} 0,68 \pm 0,18$ \\
\hline$\alpha$-amilasa en región posterior (U/l) & $\mathrm{b}, \mathrm{i} 0,43 \pm 0,24$ & ${ }^{\mathrm{i}} 0,69 \pm 0,27$ & ${ }^{\mathrm{i}} 0,78 \pm 0,13$ & ${ }^{\mathrm{i}} 0,72 \pm 0,18$ \\
\hline$\left[\mathrm{Ca}^{2+}\right]$ en región anterior $(\mathrm{mg} / \mathrm{mg})$ & f $8,64 \pm 3,97$ & ${ }^{\mathrm{f}} 4,27 \pm 3,44$ & $6,37 \pm 5,11$ & $9,91 \pm 6,34$ \\
\hline$\left[\mathrm{Ca}^{2+}\right]$ en región posterior $(\mathrm{mg} / \mathrm{mg})$ & f $9,42 \pm 4,82$ & f $4,62 \pm 4,25$ & $5,24 \pm 4,80$ & $9,37 \pm 7,57$ \\
\hline C. albicans en región anterior (UFC/mg) & $5,7 \times 10^{2} \pm 2,2 \times 10^{2}$ & $2,8 \times 10^{2} \pm 1,2 \times 10^{2}$ & $5,3 \times 10^{2} \pm 1,2 \times 10^{2}$ & $2,2 \times 10^{2} \pm 8,0 \times 10^{2}$ \\
\hline C. albicans en región posterior (UFC/mg) & $5,5 \times 10^{2} \pm 1,8 \times 10^{2}$ & $1,4 \times 10^{2} \pm 2,9 \times 10^{2}$ & $5,0 \times 10^{2} \pm 1,2 \times 10^{2}$ & $3,8 \times 10^{2} \pm 4,0 \times 10^{2}$ \\
\hline S. mutans en región anterior (UFC/mg) & ${ }^{\mathrm{a}} 1,1 \times 10^{4} \pm 1,6 \times 10^{4}$ & $2,4 \times 10^{4} \pm 1,5 \times 10^{4}$ & $3,61 \times 10^{4} \pm 3,23 \times 10^{4}$ & $3,7 \times 10^{4} \pm 2,8 \times 10^{4}$ \\
\hline S. mutans en región posterior (UFC/mg) & a, g $1,7 \times 10^{4} \pm 1,7 \times 10^{4}$ & $\mathrm{~g} 2,5 \times 10^{4} \pm 1,6 \times 10^{4}$ & ${ }^{8} 3,1 \times 10^{4} \pm 2,3 \times 10^{4}$ & $83,7 \times 10^{4} \pm 2,2 \times 10^{4}$ \\
\hline Lactobacillus spp. en región anterior (UFC/mg) & a $2,0 \times 10^{4} \pm 1,8 \times 10^{4}$ & $2,9 \times 10^{4} \pm 1,7 \times 10^{4}$ & $3,7 \times 10^{4} \pm 12,5 \times 10^{4}$ & $4,8 \times 10^{4} \pm 3,2 \times 10^{4}$ \\
\hline Lactobacillus spp. en región posterior (UFC/mg) & a $2,3 \times 10^{4} \pm 1,7 \times 10^{4}$ & $3,1 \times 10^{4} \pm 1,6 \times 10^{4}$ & $4,0 \times 10^{4} \pm 2,4 \times 10^{4}$ & $4,7 \times 10^{4} \pm 2,7 \times 10^{4}$ \\
\hline
\end{tabular}

\footnotetext{
\# Los datos se expresan como la media \pm desviación estándar. SM: sin modificaciones ND: no detectable
}

a $p<0,0001 ; b p=0,0004 ; c p=0,001 ; d p=0,001 ; e p=0,02 ; f p=0,02 ; g p=0,002 ; h p<0,0001 ;$ i $p=0,0002$. 
observó un mejoramiento significativo de la capacidad amortiguadora salival a cortos tiempos del estudio ( 1 y t2; $p<0,001)$, aunque este parámetro desmejoró a tiempos más largos $(\mathrm{t} 3)$. El pH salival mostró una disminución significativa a tiempos cortos $(\mathrm{t} 1 ; p=0,04)$.

La concentración de iones calcio disminuyó en la placa bacteriana anterior y posterior a tiempos cortos $(\mathrm{t} 1, p<$ $0,002)$ pero se observó un incremento a tiempos más largos (t3) en la placa bacteriana de la región posterior de la boca similares a los valores iniciales. El flujo salival no se modificó significativamente durante el estudio. La actividad de $\alpha$-amilasa mostró un incremento significativo y sostenido en el tiempo tanto en la saliva $(p<$ $0,002)$ como en la placa bacteriana de la zona anterior y posterior $(\mathrm{p}<0,0001, \mathrm{p}<0,0002)$.

Los niveles de los microorganismos $S$. mutans, Lactobacillus y Candida en la saliva no mostraron cambios durante los tiempos del estudio $(p>0,05)$. La colocación de aditamentos ortodónticos en los pacientes produjo un aumento significativo en los recuentos de S.mutans y Lactobacillus spp. comparado con t0 durante el estudio $(p<0,05)$, siendo la placa bacteriana de la región posterior de la boca la de mayores recuentos $(p<0,005)$. Las UFC de Candida en ambas regiones de la boca no mostraron diferencias en los tiempos estudiados. Considerando que las modificaciones de las condiciones del ambiente oral fueron observadas a partir de $t 1$, se evaluó la asociación entre las variables estudiadas a este tiempo corto de tratamiento mediante la prueba multivariada de correspondencia observada en la figura. Los parámetros clínicos, bioquímicos y microbiológicos fueron categorizados en dos grupos utilizando la mediana. Las condiciones más adversas para la salud bucal de los pacientes se asociaron entre sí, tales como el apiñamiento dental inferior, altos niveles de $\alpha$-amilasa y de calcio en la placa bacteriana, baja capacidad amortiguadora salival y altos recuentos de UFC de Lactobacillus (región posterior) y Candida spp. (región anterior). Además, se observó asociación entre los bajos valores de $\mathrm{pH}$ y flujo salival, altos niveles de S.mutans (placa bacteriana de ambas regiones de la boca), Lactobacillus spp. (placa bacteriana de la región anterior) y de IPO. En contraste, se observó asociación entre las condiciones favorables para la salud bucal, como lo son los bajos valores del IPO y $\alpha$-amilasa en placa bacteriana, bajos recuentos de $S$. mutans y Lactobacillus spp., una mejor capacidad amortiguadora y flujo salival, y ausencia de Candida spp.

\section{Discusión}

Las modificaciones en el nicho ecológico formado en la interfase aditamento ortodóntico-esmalte dental representan un sistema estresante para la homeostasis oral 2,7,24. En este trabajo, se analizaron parámetros clínicos, salivales y microbiológicos previamente y a distintos tiempos luego de la colocación de aparatología ortodóntica labial.

Los altos valores de CPO-D, IQH, IHOs y el apiñamiento dental observado en los pacientes que participaron de este trabajo denotan el alto riesgo de caries

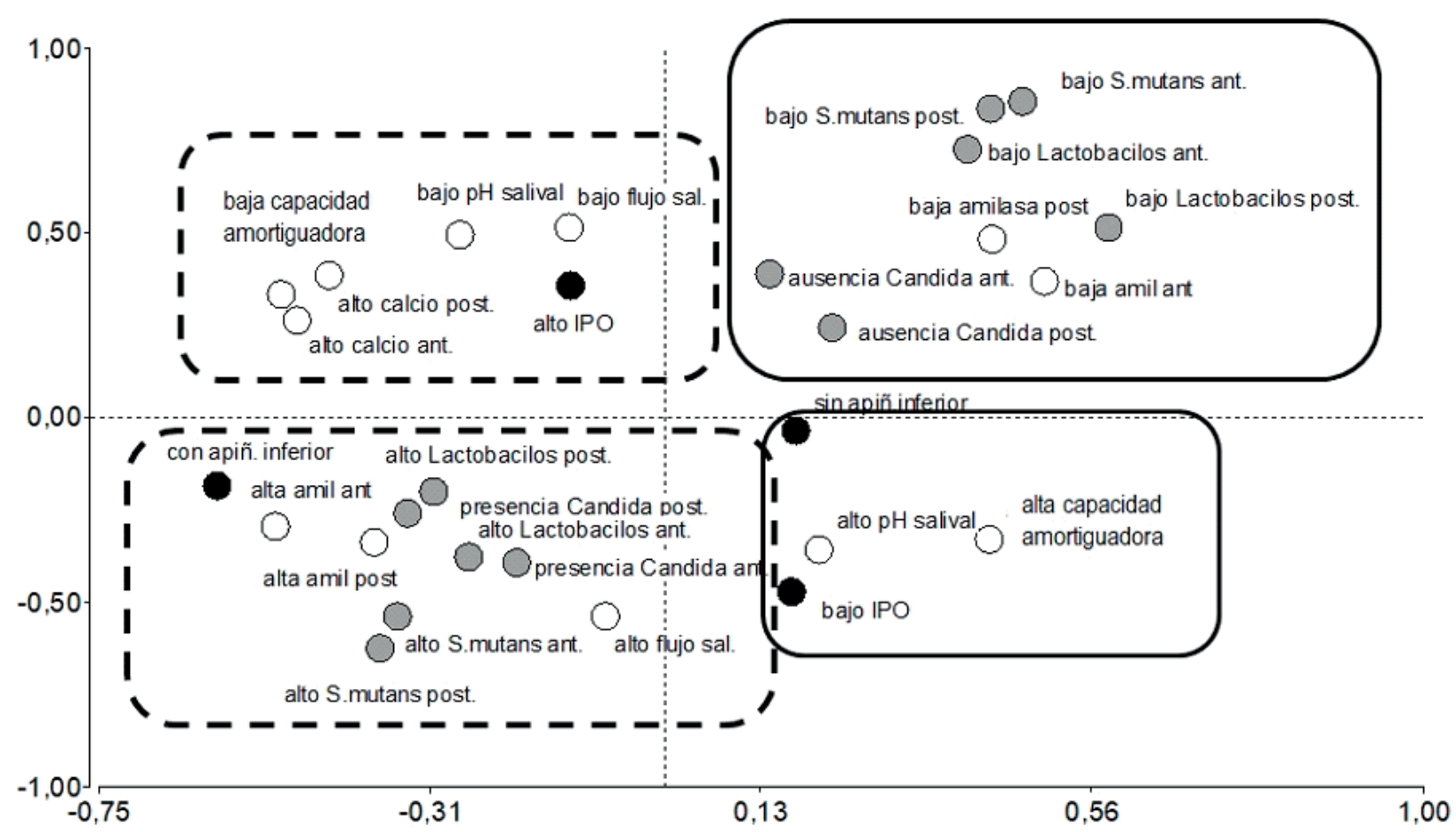

Figura. Asociación entre los parámetros clínicos, bioquímicos y microbiológicos a t1 (análisis de multivariado de correspondencia; inercia acumulada 35\%).

- parámetros clínicos $\bigcirc$ parámetros bioquímicos $\bigcirc$ parámetros microbiológicos 
antes de comenzar el tratamiento ortodóntico, en coincidencia con Lara-Carrillo et al. ${ }^{7}$. Los mayores valores de IHOs de la región posterior observados en este estudio acuerdan con Giugliano et al. ${ }^{15}$ que reportaron un mayor número de caries en esa región de la boca, reforzando la especial atención a prestar en esa zona. Estas condiciones anticipan la necesidad de un seguimiento personalizado durante el tratamiento.

Luego del pegado de los aditamentos ortodónticos, la disminución de los índices IHOs y IH observada, podría estar relacionada con la motivación del profesional tratante, como ha sido descrito por Sudarević et al. ${ }^{13}$, aunque no alcanzaron valores óptimos durante el tiempo del estudio.

Los componentes salivales son reconocidos como determinantes importantes de la salud oral y factores modificadores del pronóstico de caries. En coincidencia con Anhoury et al. ${ }^{26}$, el pH salival de los pacientes en este trabajo mostró una disminución significativa a t1 con una recuperación a tiempos más largos. Por otro lado, la capacidad amortiguadora empeoró a tiempos largos, en contraste con Cardoso et al. ${ }^{22}$ que no observó cambios en la capacidad amortiguadora salival hasta los 3 meses de colocados los aditamentos ortodónticos. Las modificaciones observadas pueden ser consideradas como una respuesta fisiológica a la presencia de un cuerpo extraño a tiempos cortos, y una posterior adaptación luego de la alteración de la homeostasis intraoral con el tiempo al estímulo prolongado ${ }^{12}$. A diferencia de Sudarević et al. ${ }^{13}$, los resultados no mostraron cambios significativos en el flujo salival.

El incremento de iones calcio observado en la placa bacteriana a $\mathrm{t} 2$ y $\mathrm{t} 3$ podría relacionarse con el descenso del $\mathrm{pH}$ en la misma y una menor capacidad de remineralización de la región aledaña a los aditamentos ortodónticos. Estos hallazgos son apoyados por estudios en la zona contigua a la aparatología fija, por el mayor riesgo de desmineralización comprobada en estudios in vitro ${ }^{26}$ y el desarrollo de lesiones de mancha blanca ${ }^{27}$.

Los menores niveles salivales de los microorganismos en comparación de los de placa bacteriana observados en este estudio concuerdan con el trabajo de Sudarević et al. ${ }^{13}$, lo que indicaría que la placa bacteriana adherida a aditamentos ortodónticos refleja mejor que la saliva los cambios en la carga microbiana, y demuestran el empeoramiento de las condiciones del ambiente bucal una vez colocada la aparatología fija, en acuerdo con Antezack et al. ${ }^{1}$. La placa bacteriana y su composición juegan un importante rol en el control de los procesos de desmineralización del esmalte dental ${ }^{28}$. La concentración de iones y enzimas en este microbioma y el carácter competitivo de $S$. mutans con otros microorganismos y por los sitios de adhesión a los tejidos orales han sido reportados como indicadores pronóstico de la caries dental ${ }^{24,26}$. Los resultados de este estudio mostraron un incremento sostenido y significativo de la $\alpha$-amilasa, tanto en la saliva como en la placa bacteriana, en especial en la región posterior de la boca, en acuerdo con otros autores ${ }^{10,22,23,29}$, re- forzando la participación de esta enzima en la adhesión bacteriana y su alta afinidad por los estreptococos orales y la vulnerabilidad de esta región bucal. Se conoce que la presencia de placa bacteriana y el recuento de bacterias cariogénicas, tales como Lactobacillus spp. y S. mutans permite identificar individuos susceptibles a la caries dental ${ }^{10,30,31}$. En acuerdo con los resultados de este estudio, Klaus et al. ${ }^{4}$ reportaron que $S$. mutans fue detectado en todos los pacientes bajo tratamiento ortodóntico. Por otro lado, y coincidentemente con este estudio, otros autores observaron que la carga bacteriana adherida a aditamentos ortodónticos y al esmalte aumentó significativamente en la región posterior de la boca (premolar/molar) comparado con la región anterior (incisivos centrales y laterales de la boca) 16,32, confirmando que el sector posterior de la boca es la región más vulnerable. La baja frecuencia de portadores de Candida spp. durante el tratamiento observada en este estudio concuerdan con los resultados de DarOdeh et al. ${ }^{8}$, que observaron la ausencia del hongo en el $72 \%$ de los pacientes luego de 4 meses de tratamiento. Topaloglu et al. ${ }^{11}$ observaron un aumento en los pacientes portadores de Candida en el seguimiento a los 6 meses de tratamiento, el número de pacientes que completaron el estudio fue muy bajo. En concordancia con este estudio, Grzegocka et al. ${ }^{33}$ describieron que el tratamiento ortodóntico promovió la colonización de las levaduras con variaciones durante el tiempo estudiado, con un bajo número de pacientes portadores. Los resultados de este estudio en coincidencia con los trabajos mencionados reflejarían la habilidad de las bacterias cariogénicas frente a Candida para competir en la supervivencia en la placa bacteriana.

Los cambios que se observaron a tiempos cortos del tratamiento ( $\mathrm{t} 1$ ) mostraron que las condiciones más adversas para la salud bucal se asociaron positivamente, especialmente en la región posterior de la boca. En coincidencia con Sudarević et al. ${ }^{13}$, la disminución observada en el IHOs durante el período estudiado en este trabajo no fue acompañada por una disminución en el recuento de la microflora cariogénica. Otro de los parámetros clínicos asociado a las peores condiciones de salud bucal fue el apiñamiento dentario que, como factor de riesgo, ha sido descrito por Staufer et al. ${ }^{34}$

Los resultados de este estudio refuerzan la necesidad de que los profesionales odontólogos evalúen minuciosa e individualmente los hábitos de higiene oral, la motivación del paciente y las condiciones del ambiente bucal, en especial la microflora cariogénica en pacientes con alto CPO-D, previo y durante el tratamiento, para aplicar medidas preventivas que disminuyan los efectos colaterales no deseados del tratamiento ortodóntico ${ }^{35}$.

En conclusión, el presente estudio muestra que desde tiempos cortos de la colocación de la aparatología fija ortodóntica, se asocian los parámetros clínicos, microbiológicos y salivales que van en contra de mantener la salud bucal, en una franca sinergia entre factores de riesgo cariogénico. 


\section{Referencias bibliográficas}

1. Antezack A, Monnet-Corti V. Hygiène orale et parodontale chez les patients porteurs de dispositifs orthodontiques [Oral and periodontal hygiene in orthodontic patients]. Orthod Fr. 2018;89(2):181-190. DOI:10.1051/ orthodfr/2018015.

2. Wishney M. Potential risks of orthodontic therapy: a critical review and conceptual framework. Aust Dent J. 2017;62 Suppl 1:86-96. DOI:10.1111/adj.12486.

3. Shukla C, Maurya R, Singh V, Tijare M. Evaluation of role of fixed orthodontics in changing oral ecological flora of opportunistic microbes in children and adolescent. J Indian Soc Pedod Prev Dent. 2017;35(1):34-40. DOI:10.4103/0970-4388.199226.

4. Klaus K, Eichenauer J, Sprenger R, Ruf S. Oral microbiota carriage in patients with multibracket appliance in relation to the quality of oral hygiene. Head Face Med. 2016;12(1):28. DOI:10.1186/s13005-016-0125-x.

5. Marsh PD. Dental plaque as a biofilm and a microbial community - implications for health and disease. BMC Oral Health. 2006;6 Suppl 1(Suppl 1):S14. DOI: 10.1186/1472-6831-6-S1-S14.

6. Lim BS, Lee SJ, Lee JW, Ahn SJ. Quantitative analysis of adhesion of cariogenic streptococci to orthodontic raw materials. Am J Orthod Dentofacial Orthop. 2008; 133(6):882-888. DOI:10.1016/j.ajodo.2006.07.027.

7. Lara-Carrillo E, Montiel-Bastida NM, Sánchez-Pérez L, Alanís-Tavira J. Effect of orthodontic treatment on saliva, plaque and the levels of Streptococcus mutans and Lactobacillus. Med Oral Patol Oral Cir Bucal. 2010;15(6):e924-e929. DOI:10.4317/medoral.15. e924.

8. Dar-Odeh N, Shehabi A, Al-Bitar Z, Al-Omari I, Badran S, Al-Omiri M, et al. Oral Candida colonization in patients with fixed orthodontic appliances: The importance of some nutritional and salivary factors. Afr J Microbiol Res 2011;5:2150-4. DOI: 10.5897/AJMR11.382.

9. Hannig C, Hannig M, Attin T. Enzymes in the acquired enamel pellicle. Eur J Oral Sci. 2005;113(1):2-13. DOI:10.1111/j.1600-0722.2004.00180.x.

10. Borghi GN, Rodrigues LP, Lopes LM, Parisotto TM, Steiner-Oliveira C, Nobre-Dos-Santos M. Relationship among $\alpha$-amylase and carbonic anhydrase VI in saliva, visible biofilm, and early childhood caries: a longitudinal study. Int J Paediatr Dent. 2017;27(3):174-182. DOI:10.1111/ipd.12249.

11. Topaloglu-Ak A, Ertugrul F, Eden E, Ates M, Bulut H. Effect of orthodontic appliances on oral microbiota--6 month follow-up. J Clin Pediatr Dent. 2011;35(4):433436. DOI:10.17796/jcpd.35.4.61114412637mt661.

12. Alessandri Bonetti G, Incerti Parenti S, Garulli G, Gatto MR, Checchi L. Effect of fixed orthodontic appliances on salivary properties. Prog Orthod. 2013;14:13. DOI:10.1186/2196-1042-14-13.

13. Sudarević K, Jurela A, Repić D, Jokić D, Mikić IM, Pejda S. Oral health changes during early phase of orthodontic treatment. Acta Clin Croat. 2014;53(4):399-404.

14. Van Gastel J, Quirynen M, Teughels W, Coucke W, Carels C. Longitudinal changes in microbiology and clinical periodontal variables after placement of fixed orthodontic appliances. J Periodontol. 2008;79(11):2078-86. DOI: 10.1902/jop.2008.080153.

15. Giugliano D, d'Apuzzo F, Majorana A, Campus G, Nucci F, Flores-Mir C, et al. Influence of occlusal characteristics, food intake and oral hygiene habits on dental caries in adolescents: a cross-sectional study. Eur J Paediatr Dent. 2018 Jun;19(2):95-100. DOI: 10.23804/ ejpd.2018.19.02.02.

16. Shpack N, Greenstein RB, Gazit D, Sarig R, Vardimon AD. Efficacy of three hygienic protocols in reducing biofilm adherence to removable thermoplastic appliance. Angle Orthod. 2014;84(1):161-70. DOI: 10.2319/012413-75.1.

17. Cerroni S, Pasquantonio G, Condò R, Cerroni L. Orthodontic Fixed Appliance and Periodontal Status: An Updated Systematic Review. Open Dent J. 2018;12:614622. DOI: $10.2174 / 1745017901814010614$.

18. Greene JC, Vermillion JR. The Simplified Oral Hygiene Index. J Am Dent Assoc. 1964;68:7-13. DOI:10.14219/ jada.archive.1964.0034.

19. Quigley GA, Hein JW. Comparative cleansing efficiency of manual and power brushing. J Am Dent Assoc. 1962;65:26-29. DOI:10.14219/jada.archive.1962.0184.

20. Zhao M, Liu M, Chen W, Zhang H, Bai Y, Ren W. Salivary microbial changes during the first 6 months of orthodontic treatment. PeerJ. 2020;8:e10446. DOI: $10.7717 /$ peerj. 10446.

21. Beberhold K, Sachse-Kulp A, Schwestka-Polly R, Hornecker E, Ziebolz D. The Orthodontic Plaque Index: an oral hygiene index for patients with multibracket appliances. Orthodontics (Chic.). 2012;13(1):94-9.

22. Cardoso AA, Lopes LM, Rodrigues LP, Teixeira JJ, Steiner-Oliveira C, Nobre-Dos-Santos M. Influence of salivary parameters in the caries development in orthodontic patients-an observational clinical study. Int J Paediatr Dent. 2017;27(6):540-550. DOI:10.1111/ipd.12295.

23. Prabhakar A, Dodawad R, Os R. Evaluation of Flow Rate, pH, Buffering Capacity, Calcium, Total Protein and Total Antioxidant Levels of Saliva in Caries Free and Caries Active Children-An In Vivo Study. Int J Clin Pediatr Dent. 2009;2(1):9-12. DOI:10.5005/jp-journals-10005-1034.

24. Lombardo L, Ortan YÖ, Gorgun Ö, Panza C, Scuzzo G, Siciliani G. Changes in the oral environment after placement of lingual and labial orthodontic appliances. Prog Orthod. 2013;14:28. DOI:10.1186/2196-1042-14-28.

25. Alshahrani I, Hameed MS, Syed S, Amanullah M, Togoo RA, Kaleem S. Changes in essential salivary parameters in patients undergoing fixed orthodontic treatment: A longitudinal study. Niger J Clin Pract. 2019;22(5):707712. DOI:10.4103/njcp.njcp_606_18.

26. Anhoury P, Nathanson D, Hughes CV, Socransky S, Feres M, Chou LL. Microbial profile on metallic and ceramic bracket materials. Angle Orthod. 2002;72(4):338-343. DOI:10.1043/0003-3219(2002)072<0338:MPOMA$\mathrm{C}>2.0 . \mathrm{CO} ; 2$. 
27. Jablonski-Momeni A, Sambale J, Gaerttner L, Nothelfer $\mathrm{R}$, Korbmacher-Steiner H. Use of bioluminescence measurements for detection of artificial demineralization adjacent to orthodontic brackets. J Orofac Orthop. 2021. DOI: $10.1007 / \mathrm{s} 00056-021-00341-\mathrm{y}$.

28. Julien KC, Buschang PH, Campbell PM. Prevalence of white spot lesion formation during orthodontic treatment. Angle Orthod. 2013;83(4):641-7. DOI: 10.2319/071712-584.1.

29. Kaczor-Urbanowicz KE, Martin Carreras-Presas C, Aro K, Tu M, Garcia-Godoy F, Wong DT. Saliva diagnostics - Current views and directions. Exp Biol Med (Maywood). 2017;242(5):459-472. DOI: $10.1177 / 1535370216681550$.

30. Singh S, Sharma A, Sood PB, Sood A, Zaidi I, Sinha A. Saliva as a prediction tool for dental caries: An in vivo study. J Oral Biol Craniofac Res. 2015;5(2):59-64. DOI:10.1016/j.jobcr.2015.05.001.

31. Al-Anezi SA, Harradine NW. Quantifying plaque during orthodontic treatment. Angle Orthod. 2012;82(4):748753. DOI:10.2319/050111-312.1.
32. Sanpei S, Endo T, Shimooka S. Caries risk factors in children under treatment with sectional brackets. Angle Orthod. 2010;80(3):509-514. DOI:10.2319/072909431.1 .

33. Grzegocka K, Krzyściak P, Hille-Padalis A, Loster JE, Talaga-Ćwiertnia K, Loster BW. Candida prevalence and oral hygiene due to orthodontic therapy with conventional brackets. BMC Oral Health. 2020;20(1):277. DOI: 10.1186/s12903-020-01267-4.

34. Staufer K, Landmesser H. Effects of crowding in the lower anterior segment - a risk evaluation depending upon the degree of crowding. J Orofac Orthop 2004;65(1):13-25.

35. Kado I, Hisatsune J, Tsuruda K, Tanimoto K, Sugai M. The impact of fixed orthodontic appliances on oral microbiome dynamics in Japanese patients. Sci Rep. 2020;10(1):21989. DOI: 10.1038/s41598-020-78971-2. 